\title{
Analyzing influential factors of Chinese Fighting Bull's cultural integration at Multicultural Society of ZheJiang
}

\author{
Lin TianHai ,Lin XaoMei \\ Physical Education Department of ZheJiang Univers ity \\ Hangzhou, China
}

\begin{abstract}
Chinese Traditional sport of Fighting Bull was evolved from Hui ethnic group and has become more and more popular through recent 3 years. The study tested influential factors of Chinese Fighting Bull's cultural integration through five predictive variables as measurement paths which is including Fighting Bull's natural and built environment, Fighting Bull's policies, Fighting Bull's embodied sportsmanship characters, national behavioral habits and national social relationships. To predict the influential factors of Chinese Fighting Bull's cultural integration, a total of 52 participants ( 33 males, 19 females) ages12 to 58years were included in the study. A questionnaire of five dimensions established to identify influential factors. The reliability and validity of such scales suggest that future influential factors study of sport's cultural integration from above five dimensions has a certain guiding significance after corrected according to the specific cultural characteristics.
\end{abstract}

Keywords- Fighting Bull; Chinese Fighting;

\section{INTRODUCTION}

Zhejiang population structure made up of ethnic Han and three ethnic minority groups of She, Hui and Man. Thus, it poses the questions of what's kind of influential factors effecting their sport's cultural integration and how sport's culture of Hui ethnic group's infiltrating to mainstream culture. In order to further understand, the research based on various Cultural hierarchy theories and conceptual framework of acculturation attitudes of Berry to establish questionnaire and test it.

\section{ASSUMING INFLUENTIAL FACTORS OF CHINESE FIGHTING BULL'S CULTURAL INTEGRATION AND DEVELOPING SCALE}

From the perspective of cultural system, Geet Hofstede suggested that cultural ecological factors include geographic, economic, demographic, genetic/hygienic, historical, technological, urbanization, value systems shared by majority and so on. Besides, he pointed out that culture and personality is a classic term for psychological anthropology (Barnouw, 1973). Furthermore, cultural traits can sometimes be measured by personality tests 1. Edgar H.Schein's hierarchy theory of needs and Berry and his colleagues have examined the relationships between variables such as language, education, socioeconomic status, ethnicity, psychological stress, and acculturation attitudes of several ethnic groups (Berry, Kim, Minde, \& Mok, 1987; Berry et al., 1989; Zheng \& Berry, 1991; Krishnan \& Berry, 1992).All

\author{
ChenYuLing \\ Li Shui College \\ Lishui, China
}

above factors could to be influential Predictors to Chinese Fighting Bull's cultural integration.

Following above influential Predictors mentioned, we secondly ran qualitative interviews with 10 Fighting Bull' $s$ participants from ZheJiang Province. Theseinterviews focused on the point of influential factors and important reasons for them to participating Fighting Bull. After all of this literature analysis and interviews, we assumed a number of the Fighting Bull participate influential factors involved education, socioeconomic status(Walseth, 2004), government policy, value systems, bridging friendship and Folk-custom and so on. Furthermore, we attempt to summarize factors in five dimensions which involves Fighting Bull' s natural and built environment, Fighting Bull' s policies, Fighting Bull' s embodied sportsmanship characters, national behavioral habits and national social relationships. To prove its rationality, we established the corresponding questionnaire and hypothesis that all of these factors will affect the Fighting Bull' s cultural integration and setting the corresponding questions. And used Likert 7 grades scale to assess it, such as natural and built environment, we asked questions on about how do you find that the natural and built environment to carry out Fighting Bull. To Fighting Bull' s sportsmanship, we have asked them that Fighting Bull embodied what $s$ kind of sportsmanship and if they seek for industrious and brave spirit through participating and if they feel stressed and more anonymous when they had not played Fighting Bull. (Walseth,2006).

Besides, we tested two independent attitudinal dimensions: whether people maintain in the host society to refuse to participant Fighting Bull or whether consider it as valuable enough to seek them out and foster them. The combination of the responses to these two dimensions (Yes or No) produces a classic matrix (see Berry et al., 1989; Berry, 1990, 2001, 2003) in which the four possible attitudes toward acculturation adopted by people are represented as: “ integration " (Yes/Yes), “ as similation " (No/Yes), “separation” (Yes/No)and “marginalisat-ion” (No/No).

\section{METHODS}

To test the reliability and validity of the scales and acculturation strategies they adopted, 52 participants (33 males, 19 females) ages 12 to 58years were included in the study. Cronbach's $\alpha$ coefficient and confirmatory factor 
analysis was used to test the testing validity and reliability of scale and to determine whether the proposed influential factors of Chinese Fighting Bull's cultural integration is a good fit to the data.

IV. Results

The Cronbach's a coefficient of first dimension on about Fighting Bull's natural and built environment(FBNBE) involved five questions is 0.733. Second dimension on about Fighting Bull's policies(SBP) included four questions' Cronbach' a coefficient is 0.836.Third dimension of Fighting Bull's embodied sportsmanship characters(FBESC) with four questions' Cronbach's a coefficient is 0.758 . Fourth dimension on about national behavioral habits' (NBH) Cronbach's is 0.628. Fifth dimension on about national social relationships' (NSR) Cronbach's a coefficient is 0.853 . The general reliability of Cronbach's a coefficient equal to 0.91 . KMO value is 0.704 and significance value is 0.00 which mean the date that is suitable for confirmatory factor analysis. Confirmatory factor analysis results retained the several dimensions except deleted three sub-questions of alleviating the pressure of life, promoting the professional skill and reward policy for participants, in addition to transferred the question of facilities equipment from FBNBE factor to SBP factor.

Besides, after tested two independent attitudinal dimensions Regarding of whether people maintain in the host society to refuse to participant Fighting Bull or consider it as valuable enough to seek them out and foster them, we found at that four possible attitudes toward acculturation adopted by people, a total of 46 people adopted integration strategy out of 52, and 6 people gave up the original sport events partially to participating Fighting Bull. Furthermore, to judge respectively the influential weight of the five factors, we found that NSR, FBESC and NBH is greater than SBP and FBNBE(as following table 1).

Table 1.summary report the influential weight of the five factors

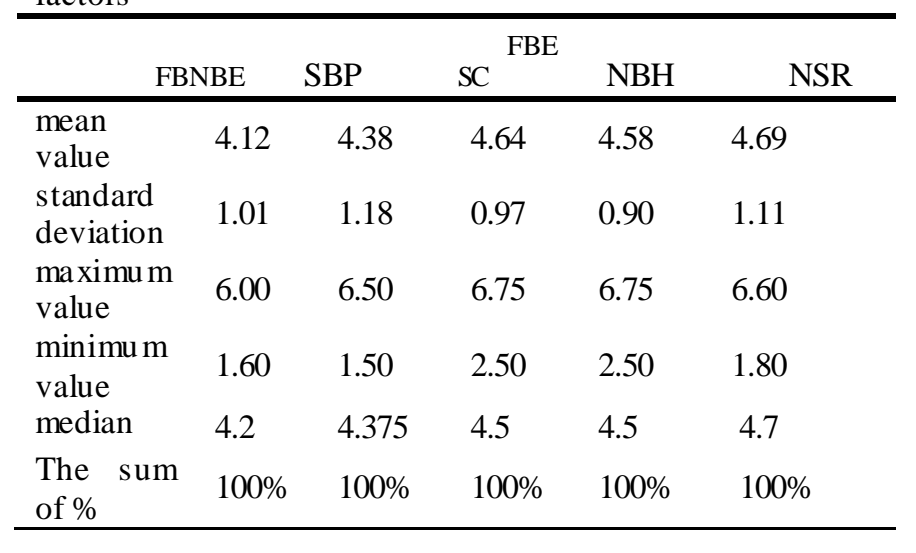

\section{DISCUSSION}

Getting rid of the question of alleviating the pressure of life from $\mathrm{NBH}$ factor may duo to high intensity and competitive of its motion feature. It is hard to achieve the purpose of relieving stress through participate in this high intensive sport. Two questions of promoting the professional skill and reward policy for participants were deleted from $\mathrm{NBH}$ and SBP may because it is only important to professional athletes of Chinese Fighting Bull. In addition to, transferred the question of facilities equipment from FBNBE factor to SBP factor may because of the most fund of Chinese Fighting Bull facilities equipment sponsored by the Chinese government.

Overall, the reliability and validity of such scales is acceptable and the five dimensions with nineteen questions have a certain reference value for future influential factors study of sport' s cultural integration.

\section{REFERENCE}

[1] Geert Hofstede, Culture and organizations [J], Intemational Studies of Management\& Organization, 1981:23-26

[2]Walseth, K. and Fasting, K. Sport as a Means of Integrating Minority Women [J], Sport in Society,2004(7): 109 - 29.

[3]Walseth, K. Bridging and Bonding Friendship in Sport: The Experience of Young Women with Immigrant Background[J].Sport, Education \& Society. 2008, pp. 1-17

[4]Walseth, K. Young Muslim Women and Sport: The Impact of Identity Work[J], Leisure Studies (2006).25(1): 75 - 94.

[5] J. W. Berry. Acculturation and Adaptation in a New Society. International Migration[J]. Volume 30, Issue Supplement s 1, pages 69 - 85, June 1992

[6]Marisol Navasa, A.J.R.M., Acculturation strategies and attitudes according to the Relative Acculturation Extended Model (RAEM): The pers pectives of natives versus immigrants. International Journal of Intercultural Relations [J], 2007(31): p. $67-86$.

[7]Berry, J.W., Immigration, acculturation, and adaptation[J]. Applied psychology, 1997(1): p 7

[8]Berry, J.W., Immigration, acculturation, and adaptation[J]. Applied psychology, 1997. 46(1): p. 19

[9] Frogner, E. 'On Ethnic Sport Among Turkish Migrants in the Federal Republic of Germany' [J], Intemational Review for the Sociology of Sport.1985:75 - 85.

[10] Klein, M.-L. and Kothy, J. 'Social Conflicts in Interetnic Sport Contacts: A comparative Study in Local Football Leagues' , [J].paper presented at the 6th Annual Congress of the European College of Sport Science, 24 - 8 July(2001), Cologne.

[11] Walseth, K., sport and belonging. International Review for the Sociology of Sport[J], 2006: p. $447-464$

[12]Elling, A., De Knop, P. and Knoppers, A. 'The Social Integrative meaning of Sport: A Critical and Comparative Analys is of Policy and Practice in the Netherlands, [J], Sociology of Sport Journal2001 (18): 414 - 34. 